\title{
IMPLEMENTASI TANGGUNGJAWAB NEGARA BERKAITAN DENGAN HAK ATAS PENDIDIKAN DASAR BAGI WARGA NEGARA DI DESA TERPENCIL KABUPATEN BANGLI
}

Oleh:

Ni Ketut Sri Utari, I Made Udiana

\begin{abstract}
The purpose of this study is to analyze the implementation of Article 31 (2) of the Constitution 1945 concerning the right of education for citizens, especially in remote village of Bangli Regency, Bali Province. The type of this research is empirical legalresearch. The study showed that the Government has provided a central school in one building both for elementary and junior high school so called "Satap" (School in one roof) in order to fulfill its constitutional obligation for the people in slop of mountains in the remote village of Bangli Regency. For this efforts are supported by education funding of the National Government distributes budget operational school (BOS), grants of educational facilities from Government Budget of Bali Province (APBD Bali) as well as Block Grand from the National Government Budget $(A P B N)$. However, those budgets are still considered relatively very small. For the better implementation of the right of education, therefore the efforts of government need to be improved as well as budgeting for the remote village should be prioritized, increased and supervised.
\end{abstract}

Keywords: state responsibility, basic education, remote village.

\section{PENDAHULUAN}

\subsection{Latar Belakang Masalah}

Amanat Pasal 31 ayat 2 UUD NRI

1945, Pasal 34 Undang-Undang Nomor 20

Tahun 2003 Tentang Sistem Pendidikan Nasional, dan PP No.47 Tahun 2008 Tentang Wajib Belajar menetapkan bahwa Pemerintah dan pemerintah daerah menjamin terselenggaranya program wajib belajar minimal pada jenjang pendidikan dasar (SD dan SMP) tanpa memungut biaya. Di sisi lain kondisi pengunungan di Kabupaten Bangli juga diungkap dalam Bali Post ${ }^{1}$

Kepala Desa Subaya Nyoman Diantara mengungkapkan bahwa program wajib belajar 9 tahun yang selama ini digalakkan

Bali Post Senen, 14 Juli 2014. Tempat Sekolah Jauh Tiap Tahun Belasan Siswa SD di Subaya Tak Melanjutkan.hlm.15. kol 2,3,4,5,6. pemerintah belum bisa berjalan sepenuhnya didesanya. Angka putus sekolah sangat tinggi.

- Tahun 2012 dari 22 siswa yang lulus SD tak seorangpun melanjutkan ke SMP

- Tahun 2013 dari 20 siswa yang lulus SD hanya 2 orang yang melanjutkan ke SMP

- Tahun 2014 dari 17 orang yang lulus SD hanya 4 orang yang melanjutkan ke SMP. Ada beberapa faktor yang berpengaruh, yang terutama kemiskinan, jauhnya tempat sekolah (sekitar 8 kilo dan belum ada transportasi umum dan jalan belum memadai). Dalam usia muda mereka bekerja jadi buruh pengaspal jalan, petani dan pembantu rumah tangga di daerah perkotaan. 
Bali yang merupakan destinasi pariwisata, yang menyumbang banyak pada penerimaan negara ternyata dipelosok desa masih saja belum terpenuhinya hak atas wajib belajar 9 tahun dengan beragam alasan dan faktor utama adalah: ${ }^{2}$

\section{- kemiskinan masyarakat,}

- kondisi wilayah

- di pihak pemerintah dan Satuan Pengelola Pendidikan Dasar belum optimal memberi data yang valid dan mutakhir, dan

- kepincangan APBD antar Kabupaten/ Kota,

- disamping karena ada penyalahgunaan atau belum tepat sasaran.

Upaya yang harus dilakukan adalah kasuistik per- Kabupaten/ Kota dan Sekolah. Kata kunci adalah akurasi pendataan secara menyeluruh dari lapisan terbawah sangat penting, sehingga perencanaan menyentuh kebutuhan nyata dan realisasinya bisa tepat sasaran. Dari faktor-faktor penyebab yang diuraikan di atas menarik untuk diteliti bagaimana pelaksanaan dan hambatan apa yang dihadapi oleh Pemerintah Kabupaten Bangli dan solusi pemecahan masalah yang ada dalam usaha memenuhi tanggungjawab Negara terhadap Kewajiban Konstitusional Warga Negara Warga Negara Mengikuti Pendidikan Dasar.Dipilihnya Kabupaten Bangli dengan pertimbangan bahwa APBD Kabupaten kecil serta wilayahnya berbukit sehingga banyak desa-desa/ daerah terpencil dibalik bukit, yang kemungkinan anak-anak tidak masuk sekolah atau putus sekolah. Apa

Ni Ketut Sri Utari, dkk.2014. Penelitian: Implementasi Tanggungjawab Negara Terhadap Kewajiban Konstitusional Warga Negara Mengikuti Pendidikan Dasar, Program Studi Magister (S2) Ilmu Hukum Unud.Denpasar Terhadap Kewajiban Konstitusional Warga Negara Mengikuti Pendidikan Dasar. langkah pemerintah dalam upaya memenuhi hak atas wajib belajar sembilan tahun seperti amanat UUD NRI 1945 dan bagaimana peran pemerintah Provinsi Bali dan Pemerintah dalam mengatasi masalah tersebut.

\subsection{Rumusan Masalah}

1. Bagaimana pengelolaan dan pemenuhan hak atas pendidikan dasar di Kabupaten Bangli?

2. Kendala-kendala apakah yang dihadapi berkaitan dengan pengimplementasian tanggungjawab negara terhadap pemenuhan hak warga negara memperoleh pendidikan dasar di desa terpencil Kabupaten Bangli ?

3. Bagaimana bentuk koordinasi dengan Pemerintah Propinsi Bali dalam pemecahan masalah pemenuhan hak atas pendidikan dasar?

\subsection{Tujuan penelitian:}

1. Menggali dan menganalisis pengelolaan dan pemenuhan hak atas pendidikan dasar di Kabupaten Bangli

2. Menelusuri dan menganalisis hambatan dan solusi dalam pemenuhan hak wajib belajar pendidikan dasar bagi warganya.

3. Mengungkap hubungan koordinasi antara Pemerintah Pusat; pemerintah Propinsi dan Kabupaten dalam pemenuhan kewajiban konstitusional atas hak memperoleh pendidikan dasar.

\section{TINJAUAN PUSTAKA}

Pasal 28 C ayat (1) UUDNRI 1945 dan Pasal 31 (1) UUDNRI 1945 menekankan bahwa hak mendapatkan pendidikan adalah hak asasi manusia.Khusus dalam Pasal 
31 (2) UUDNRI 1945 menentukan setiap warga negara wajib mengikuti pendidikan dasar dan pemerintah wajib membiayainya. Jadi khusus kepada warga negara Indonesia ada kewajiban atau keharusan mengikuti pendidikan dasar dan pemerintah wajib membiayai, dengan asumsi akan melahirkan warga negara yang cerdas, bisa membaca, berhitung, membaca dan menulis.

Pendidikan adalah proses pembelajaran dan pengalaman, baik mengenai keterampilan/ keahlian, kesehatan fisik maupun moralitas. Manusia tumbuh selalu melalui proses belajar, sehingga kewajiban memberi pendidikan tidak hanya kewajiban keluarga atau orang tua, juga masyarakat dan negara.

Kebijakan Nasional mengenai pendidikan diatur dalam UU No. 20Tahun 2003 Tentang Sistim Pendidikan Nasional. Pasal 1 angka 1 merumuskan: Pendidikan adalah usaha sadar dan terencana untuk mewujudkan suasana belajar dan proses pembelajaran agar peserta didik secara aktif mengembangkan potensi dirinya untuk memiliki kekuatan spriritual keagamaan, pengendalian diri, kepribadian, kecerdasan, akhlak mulia, serta keterampilan yang diperlukan dirinya, masyarakat, bangsa dan negara.

Penyelenggaraan sistem pendidikan Nasional adalah dalam rangka mencapai tujuan negara yakni mencerdaskan kehidupanbangsa.Penyelenggara pendidikan bukan hanya tugas negara, tetapi juga tugas orangtua atau keluarga dan masyarakat. Peran masyarakat terutama dalam pendirian sekolah-sekolah suasta dalam bentuk yayasan.

Penyelenggaraan pendidikan nasional setelah era reformasi didasarkan atas prinsip demokrasi (pemerataan pendidikan), desentralisasi,keadilandanmenjunjungtinggi hak asasi manusia dalam kehidupan bangsa dan negara.Prinsip-prinsip ini berdampak pada kandungan, proses dan managemen sistem pendidikan nasional.(Pasal $4 \mathrm{UU}$ No.20 Tahun 2003).

$$
\text { Pendidikan nasional berfungsi }
$$

mengembangkan kemampuan dan membentuk watak serta peradaban bangsa yang bermartabat agar peserta didik dapat mengembangkan potensinya menjadi manusia yang beriman dan bertakwa kepada Tuhan Yang Maha Esa, berakhlak mulia, sehat, berilmu, cakap, kreatif, mandiri dan menjadi warga negara yang demokratis serta bertanggung jawab.(Pasal 3 UU No.20 Tahun 2003)

Setiap warga negara yang berusia tujuh sampai lima belas tahun wajib mengikuti pendidikan dasar (Pasal 6 UU No.20 Tahun 2003). Orang tua dari anak usia wajib belajar, berkewajiban memberikan pendidikan dasar kepada anaknya. Yang dimaksud dengan pendidikan dasar adalah jenjang pendidikan yang melandasi pendidikan menengah, seperti Sekolah Dasar dan Madrasah Ibtidiyah (MI) atau bentuk lain yang sederajat serta sekolah menengah pertama (SMP) dan Madrasah Tsanawiyah atau bentuk lain yang sederajat.(Pasal 17 UU No.20 Tahun 2003).Jadi pada prinsipnya tanggungjawab terhadap pemenuhan hak atas pendidikan adalah tanggungjawab orang tua, masyarakat dan negara.Khusus untuk pendidikan dasar adalah kewajiban negara untuk membiayai.

\section{METODE PENELITIAN}

3.1 Tipe Penelitian: Pada dasarnya tipe penelitian ini adalah tipe penelitian hukum empiris, karena meneliti adanya 
(das sein), bagaimana pelaksanaan senyatanya di Kabupaten Bangli, khususnya berkaitan dengan desa desa yang letaknya di pegunungan.

3.2 Lokasi Penelitian: Dipilihnya Kabupaten Bangli dengan pertimbangan bahwa wilayahnya pegunungan dan penduduk tersebar dibalik bukit, APBD rendah dan banyak anak-anak yang putus sekolah karena kemiskinan dan jauhnya letak sekolah dari tempat tinggal mereka. Disamping itu Kabupaten Bangli letaknya paling dekat dari Denpasar, dan kabupaten ini ada diwilayah pegunungan Bali Tengah yang berbukit dan dataran tinggi.Walaupun dalam kenyataan yang banyak menyumbang anak putus sekolah adalah Kabupaten Buleleng dan Karangasem, Kabupaten Bangli dianggap dapat mewakili penduduk pegunungan di Bali.Tujuannya untuk mengenali faktor hambatan dan upaya yang dilakukan dalam mengatasi persoalan pemenuhan tanggungjawab negara terhadap hak mendapat pendidikan dasar 9 tahun.

3.3 Sumber data: Sumber data penelitian ini adalah data primer dan data sekunder. Data primer diperoleh dari pejabat yang terkait sebagai informan: Dinas Pendidikan dan Olahraga (Diskikpora) Propinsi Bali; Dinas Pendidikan dan Olahraga Kabupaten Bangli.Data sekunder bersumber dari koran, berita, peraturan perundang-undangan dan media internet.

3.4 Tehnik Pengumpulan Data: Tehnik pengumpulan data primer dengan metode wawancara terstruktur dengan pedoman wawancara.Hal ini dirasa cukup karena terkait dengan kebijakan pemerintah.Untuk data sekunder dengan melakukan penelusuran peraturan perundang-undangan dan kebijakan di bidang pendidikan dan penelusuran bahan bacaan lainnya.

3.5 Tehnis analisis data: Data yang diperoleh ada dua macam: data kualitatif dan data kuantitatif, tetapi dianalisis secara kualitatif, yakni pada kualitas atau isi data.Data kualitatif ini kemudian, diklasifikasi dan dianalisis berdasarkan klasifikasi permasalahan dalam penelitian. Setelah dideskripsikan dilakukan evaluasi dan argumentasi dan ditarik kesimpulan. Hasil penelitian ini bersifat deskriptif analisis yang akan memberi gambaran tentang implementasi pemenuhan hak konstitusional anak untuk mengikuti pendidikan dasar

\section{HASIL DAN PEMBAHASAN}

\subsection{Sumber Daya dan Kebijakan} Pengelolaan Pendidikan Dasar di Kabupaten Bangli

Kabupaten Bangli memiliki penduduk sebanyak 213.808 orang dan luas wilayahnya 520,81 kilometer (data 2010). Wilayahnya terdiri dari dataran tinggi pegunungan, tidak memiliki pantai. yang terdiri dari 4 kecamatan: Kecamatan Bangli, Kecamatan Kintamani, Kecamatan Susut, Kecamatan Tembuku.Kecamatan Kintamani memiliki wilayah yang paling luas dan penduduknya tersebar di lereng-lereng bukit dan lembah yang letaknya terpencil di sekitar Danau Batur. Alamnya yang sejuk dan cantik menjadi objek pariwisata dan salah satunya adalah Penelokan, Bukit Penulisan, Desa Trunyan yang sudah sangat terkenal, dan 
objek wisata lainnya.Salah satu desa yang lokasinya sangat jauh terpencil adalah Desa Blantih dan Desa Subaya di Kecamatan Kintamani, tetapi masih bisa terjangkau dengan alat transportasi, sehingga, menurut Bapak Drs. I Nyoman Subrata,M.M Kabiddikdas Propinsi Bali bahwa di Bali katagori desa terpencil sudah dihapus ${ }^{3}$. Kabupaten Bangli memiliki sekolah dasar sebanyak 119 SD.

$\begin{array}{lll}\text { No. } & \text { Kecamatan } & \text { Jumlah SD } \\ 1 & \text { Bangli } & \text { 34 SD } \\ 2 & \text { Susut } & \text { 14 SD } \\ 3 & \text { Tembuku } & \text { 21 SD } \\ 4 & \text { Kintamani } & \text { 52 SD } \\ \text { Jumlah } & 119 \text { SD }\end{array}$

Jumlah siswa $\mathrm{SD}=22.814$ orang dan siswa $\mathrm{SMP}=10.994$ orang.

APBD Kabupaten Bangli, khususnya PAD sangat terbatas dan belum mampu memberikan bea siswa bagi siswa miskin. Semua guru/pegawai PNS sudah dianggarkan dan digaji dari Dana Alokasi Umum dan pegawai/ guru honor Kabupaten dibebankan pada APBD Kabupaten Bangli. ${ }^{4}$

\subsection{Kendala-kendala dan Solusi terhadap masalah yang dihadapi Kabupaten Bangli.}

Kendala utama adalah kecilnya APBD dan wilayah yang luas dan berbukit serta penduduk tersebar di antara bukit-bukit. Biaya oprasional sekolah tergantung pada dana BOS dan sumbangan orangtua siswa (yang diputuskan oleh Kepala Sekolah dan

Bapak Drs. I Nyoman Subrata,M.M Kepala Bidang Pendidikan Dasar Disdikpora Propinsi Bali, dalam wawancara Senen, 21 September 2015, jam. 10.30 di Kantor Disdikpora Propinsi Bali.

4 I Nengah Danta Haryana,S.Pd,MA. Kabid Dikdas Kabupaten Bangli, wawancara hari Selasa 29 September 2015, jam 10.00 di Kantor Dikdispora Kabupaten Bangli.
Komite sekolah). Dalam upaya mengatasi wilayah yang terpecil dan jarak yang jauh di Kabupaten Bangli dibentuk sekolah satu atap, yakni SD dan SMP seperti:

Tabel 3. Sekolah Satu Atap di Kabupaten Bangli.

\begin{tabular}{|c|c|c|}
\hline NO & $\begin{array}{l}\text { KECA } \\
\text { MATAN }\end{array}$ & NAMA SEKOLAH \\
\hline 1. & Susut & Satap Pengiyangan \\
\hline 2. & $\begin{array}{l}\text { Tembu } \\
\text { ku }\end{array}$ & Satap Desa Kubu Suwih \\
\hline 3. & Kintamani & 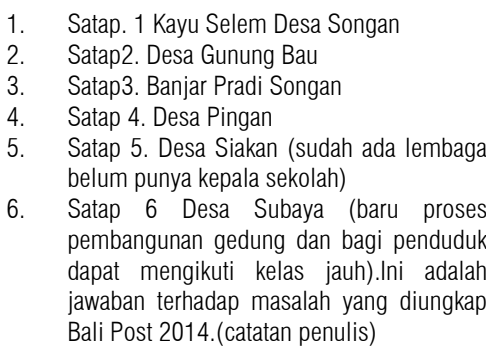 \\
\hline
\end{tabular}

Sumber: I Nengah Danta Haryana,S.Pd,MA

Tujuan membentuk Satap ini agar anakanak dapat bersekolah sampai SMP dan tetap bisa membantu orang tua mencari nafkah di kampungnya, seperti bertani, berkebun dan beternak. Kalau toh nanti mencari pekerjaan ke kota, mereka lebih dewasa dalam pendidikan.Pemda Kabupaten Bangli berusaha mendorong agar Kepala-kepala sekolah dan jajarannya di kecamatan dan desa aktif berpartisipasi melakukan pendataan anak-anak terutama untuk mencegah anak putus sekolah.Pembentukan Satap 6 Desa Subaya (baru proses pembangunan gedung dan bagi penduduk dapat mengikuti kelas jauh) adalah solusi bagi pemenuhan hak atas pendidikan dasar.

\subsection{Bentuk Koordinasi dengan Pemerintah Propinsi Bali dan Pemerintah Pusat}

Untuk mengatasi kesenjangan pendidikan antara perdesaan dan 
perkotaan,Pemerintah Pusat, Propinsi dan Kabupaten bekerja bersama-sama dan melakukankoordinasibaik mengenaifasilitas sarana pendidikan maupun sumber daya guru. Trobosan yang dilakukan pemerintah untuk biaya pendidikan dasar adalah melalui pemberian dana hibah.

Untuk lebih memudahkan memahami mengenai dana hibah untuk sekolah dan bea siswa untuk masyarakat miskin dapat dilihat dalam tabel berikut.

Tabel 4. DANA HIBAH PENDIDIKAN DASAR KABUPATEN/KOTA

\begin{tabular}{|c|c|c|c|}
\hline Sumber & Nama & Cara penyaluran & Besarnya \\
\hline \multirow[b]{2}{*}{$\begin{array}{l}\text { AP } \\
\text { BN }\end{array}$} & Dana BOS & $\begin{array}{l}\text { Diberikan langsung oleh } \\
\text { pemerintah pusat untuk } \\
\text { biaya oprasional sekolah } \\
\text { diterima lewat rekening } \\
\text { sekolah }\end{array}$ & $\begin{array}{l}\text { Rp. } 800.000 \text { untuk } \\
\text { SD x jumlah siswa } \\
\text { SMP Rp. } 1000.000\end{array}$ \\
\hline & $\begin{array}{lllll}\mathrm{H} & \mathrm{i} & \mathrm{b} & \mathrm{a} & \mathrm{h} \\
\mathrm{B} & \mathrm{I} & \mathrm{O} & \mathrm{C} & \mathrm{k} \\
\text { Grand } & & \end{array}$ & $\begin{array}{l}\text { Langsung dari } \\
\text { pemerintahPusat, satuan } \\
\text { pendidikan/sekolah } \\
\text { akan menyampaikan } \\
\text { proposalnya langsung ke } \\
\text { pemerintah pusat, dan } \\
\text { dipertanggungjawabkan } \\
\text { oleh satuan pendidikan } \\
\text { tersebut, }\end{array}$ & $\begin{array}{l}\text { Sesuai dengan isi } \\
\text { proposal }\end{array}$ \\
\hline \multirow[t]{2}{*}{$\begin{array}{l}\text { A P B D } \\
\text { Provinsi } \\
\text { Bali }\end{array}$} & $\begin{array}{l}\text { Bea Siswa } \\
\text { Miskin }\end{array}$ & $\begin{array}{l}\text { Usulan datang dari } \\
\text { sekolah, kekecamatan } \\
\text {, dinas Kabupaten dan } \\
\text { sampai ke provinsi, } \\
\text { oleh propinsi ditetapkan } \\
\text { dengan SK tentang siapa } \\
\text { yang berhak menerima, } \\
\text { penyaluran bea siswa } \\
\text { ini kemudian disalurkan } \\
\text { lewat sekolah dan } \\
\text { pengawasan/ verifikasi } \\
\text { dilakukan oleh Diknas } \\
\text { Provinsi }\end{array}$ & $\begin{array}{l}\text { SiswaSDRp.620.000/ } \\
\text { tahun } \\
\text { SMP Rp.890.000,-- } \\
\text { pertahun }\end{array}$ \\
\hline & $\begin{array}{l}\mathrm{H} \text { i b a h } \\
\text { B a n s o s } \\
\text { u } n \mathrm{t} \text { u k } \\
\text { Kabupaten } \\
\text { d a } n \\
\text { sekolah }\end{array}$ & $\begin{array}{l}\text { Diselenggarakan oleh } \\
\text { Disdikpora Provinsi, } \\
\text { sarana dan prasarana } \\
\text { langsung dan diawasi } \\
\text { juga oleh Disdikpora } \\
\text { Provinsi }\end{array}$ & Lihat Tabel.8 \\
\hline
\end{tabular}

Sumber: wawancara dengan Kepala Bidang Dikdas Provinsi Bali.
Untuk
melihat
bagaimana

implementasi kebijakan Pemerintah Pusat dalam mengalokasikan Dana BOS dapat dilihat dalam Tabel 5 dan 6,7 berikut ini
Tabel.5. REKAPITULASI BOS TIAP KABUPATEN/KOTA TAHUN 2015 UNTUK SEKOLAH NON TERPENCIL

\begin{tabular}{|c|c|c|c|c|c|c|}
\hline \multirow[t]{2}{*}{ No. } & \multirow[t]{2}{*}{ Kab/Kota } & \multicolumn{2}{|c|}{ Jumlah Siswa } & \multicolumn{3}{|c|}{$\begin{array}{l}\text { Jumlah Dana } \\
\text { per-jutarupiah }\end{array}$} \\
\hline & & SD & SMP & SD & SMP & Total \\
\hline 1 & Badung & 59.115 & 26.496 & 47.292. & 26.496. & 73.788. \\
\hline 2. & Bangli & 22.814 & 10.994 & $18.251,2$ & 10.944 & $29.195,2$ \\
\hline 3. & Buleleng & 69.813 & 34.426 & $55.850,4$ & 34.426 . & $90.276,4$ \\
\hline 4. & Gianyar & 47.638 & 22.167 & $38.110,4$ & 22.167. & $60.277,4$ \\
\hline 5. & Jembrana & 25.258 & 12.294 & $20.206,4$ & 12.294 & $32.500,4$ \\
\hline 6. & Karang asem & 45.600 & 20.339 & 36.480. & 20.339 & 56.819. \\
\hline 7. & Klungkung & 17.838 & 9.385 & $14.270,4$ & 9.385 & $23.655,4$ \\
\hline 8. & Tabanan & 37.877 & 19.821 & $29.805,6$ & 19.821. & $49.626,6$ \\
\hline 9. & Denpasar & 83.742 & 37.877 & $66.993,6$ & 37.877. & $104.870,6$ \\
\hline \multicolumn{2}{|c|}{ Total Prov. Bali } & 409.075 & 193.749 & 327.260 . & 193.749. & 521.009 . \\
\hline
\end{tabular}

Dana BOS ini untuk biaya oprasional sekolah dan tiap sekolah memperoleh sebanyak jumlah siswa kali tarif yakni SD Rp.800.000 x siswa, sedangkan SMP/ sederajat Rp.1000.000 x siswa/tahun. Untuk sekolah-sekolah yang jumlahnya siswanya kurang dari 60 orang, tetap dihitung 60 orang, karena biaya oprasional setiap sekolah hampir sama. ${ }^{5}$ Ketentuan ini menguntungkan untuk sekolah-sekolah yang terpencil di pegunungan,khususnya Kabupaten Bangli.

Pemerintah Provinsi Bali dalam APBD juga meluncurkan Hibah berupa Bea Siswa Miskin (BSM) yang diterima oleh siswa yang orang tuanya miskin sesuai dengan persyaratan yang ada, dan Bantuan Sarana kepada sekolah-sekolah di kabupaten/ kota di Bali.

Peraturan Menteri Pendidikan dan Kebudayaan RI No.161 Tahun 2014 tentang Juknis Penggunaan dan Pertanggungjawaban Dana Bos 2015., diunduh dari www.bos.kemendikbud.go.id, 19-Oktober 2015 
Tabel.6. REKAP BEASISWA SISWA MISKIN JENJANG SD TAHUN 2015

\begin{tabular}{|l|l|l|l|l|}
\hline \multirow{2}{*}{ NO } & \multirow{2}{*}{$\begin{array}{l}\text { KABUPATEN / } \\
\text { KOTA }\end{array}$} & $\begin{array}{l}\text { KUOTA } \\
\text { JUMLAH } \\
\text { SEKOLAH }\end{array}$ & $\begin{array}{l}\text { JUM } \\
\text { LAH } \\
\text { SISWA }\end{array}$ & $\begin{array}{l}\text { JUMLAH } \\
\text { DANA } \\
\text { (Rp1.000) }\end{array}$ \\
\hline 1 & BULELENG & 439 & 25,184 & $15,614,080$, \\
\hline 2 & JEMBRANA & 174 & 3.395 & 2.104 .900$. \\
\hline 3 & TABANAN & 265 & 4.303 & $2,667.860$, \\
\hline 4 & BADUNG & 172 & 1768 & 1.096 .160$. \\
\hline 5 & GIANYAR & 217 & 2.923 & 1.812 .260$. \\
\hline 6 & BANGLI & 119 & 4.172 & 2.586 .640$. \\
\hline 7 & KLUNGKUNG & 84 & 1,590 & $985,800$. \\
\hline 8 & KARANGASEM & 328 & 12,905 & 8.001 .100$. \\
\hline 9 & DENPASAR & 21 & 79 & 48.980. \\
\hline TOTAL & & & 56.319 & $34,917,780$, \\
\hline
\end{tabular}

Sumber: Data Bidang Dikdas Dikdispora Prov Bali

Tabel.7. REKAP BEASISWA SISWA MISKIN JENJANG SMP TAHUN 2015

\begin{tabular}{|l|l|l|l|r|}
\hline \multirow{2}{*}{ NO } & \multirow{4}{*}{$\begin{array}{l}\text { KABU } \\
\text { PATEN }\end{array}$} & \multicolumn{3}{|l|}{ KUOTA } \\
\cline { 3 - 5 } & /KOTA & $\begin{array}{l}\text { JUM } \\
\text { LAH } \\
\text { SEKO } \\
\text { LAH }\end{array}$ & $\begin{array}{l}\text { JUM } \\
\text { LAH } \\
\text { SISWA }\end{array}$ & $\begin{array}{l}\text { JUMLAH } \\
\text { DANA } \\
\text { (Rp1.000) }\end{array}$ \\
\hline 1 & BULELENG & 69 & 9,311 & $8,286,790$, \\
\hline 2 & JEMBRANA & 21 & 960 & 854,400, \\
\hline 3 & TABANAN & 31 & 989 & 880,210, \\
\hline 4 & BADUNG & 14 & 566 & 503,740, \\
\hline 5 & GIANYAR & 37 & 1,400 & $1,246,000$, \\
\hline 6 & BANGLI & 27 & 2,150 & $1,913,500$, \\
\hline 7 & KLUNGKUNG & 22 & 1,304 & $1,160,560$, \\
\hline 8 & KARANGASEM & 45 & 4,317 & $3,842,130$, \\
\hline 9 & DENPASAR & 8 & 69 & 61,410, \\
\hline TOTAL & & 274 & 21,066 & $18,748,740$, \\
\hline
\end{tabular}

Sumber: Data Bidang Dikdas Dikdispora Prov Bali

Dari data di atas dapat dilihat urutan siswa penerima BSM paling banyak adalah Kabupaten Buleleng, Kabupaten Karangasem dan yang ketiga adalah Kabupaten Bangli, keempat Kabupaten
Tabanan yang wilayahnya terdiri dari perbukitan dan berbatasan satu dengan lainnya.Syarat-syarat untuk memperoleh BSM diprioritaskan kepada keluarga miskin yang terdaftar sebagai KK yang mendapat tunjangan sosial (data Dinas Sosial) dan bagi yang tidak terdaftar juga dimungkinkan apabila memenuhi kriteria yang ditetapkan dalam Keputusan Kepala Disdikpora Propinsi Bali ${ }^{6}$.

Dari penelusuran asal penerima BSM Kabupaten Bangli, maka Kecamatan Kintamani sekolah desa terpecil yang paling banyak menerima BSM seperti: SDN Blandingan $=110$ orang; SDN Subaya $=$ 121 orang; SDN Songan $5=77$ orang; SDN Songan $6=117$ orang; SDN Songan $7=$ 103 orang; SDN Songan $8=60$ orang; SDN Trunyan $2=75$ orang; SDN Trunyan $3=75$ orang; SDN 6 Yang Api = 117 orang

Kabupaten Bangli dalam rangka wajib belajar menerima hibah tahun 2015 sebagai berikut:

- BSM SD sebesar Rp. 2.586.640.000; SMP sebesar Rp 1,913,500,000

Bantuan Prasarana dari Provinsi Bali sebesar Rp. 1.523.000.000.

Hibah dari Pemerintah Pusat berupa BOS SD dan SMP Rp. 29.195.200.000

Hibah Block Grand (untuk Kabupaten Bangli ada 2: Sekolah Satu Atap Tembuku dan SMP Gurukula di Kubu, masing-masing memperoleh sebesar Rp.295.154.000,- kali $2=$ Rp.590.308.000.

Syarat-syarat pemberian Bea Siswa Bagi Siswa Miskin SD,SPM,SMA dan SMK. Ditetapkan di Denpasar 23 Oktober 2014 Oleh Kepala Dinas Pendidikan Pemuda dan Olahraga Propinsi Bali TIA Kusuma Wardani,SH,MM diunduh dari www.baliprov.go.id 25 Agustus 2015 Tentang Syarat BSM. 
Dari apa yang tersaji di atas koordinasi dan sinkronisasi data perencanaan, pelaksanaan dan evaluasi penyelenggaraan Wajib Belajar antara Kabupaten (dengan jajarannya terbawah), Provinsi dan Pemerintah pusat harus selalu bekerjasama dengan baik.Ujung tombak realisasi perencanaan wajib belajar adalah Pemerintah Kabupaten. Pembagian wewenang dan tugas antara Pemerintah, Provinsi dan Kabupaten secara sederhana dapat digambarkan dalam tabel berikut:

Tabel 8: PEMBAGIAN URUSAN PEMERINTAHAN ANTARA PEMERINTAH, PROPINSI, KABUPATEN/ KOTA MENGENAI WAJIB BELAJAR

\begin{tabular}{|c|c|c|}
\hline No & Wewenang & Tugas \\
\hline 1. & Pemerintah Pusat & $\begin{array}{l}\text { - } \quad \text { Menentukan kebijakan nasional } \\
\text { - } \quad \text { standar Nasional } \\
\text { - } \quad \text { Menangani masalah lintas provinsi }\end{array}$ \\
\hline 2 & Provinsi & $\begin{array}{lll}\text { - } & \text { Melaksanakan kebijakan } \\
& \text { pemerintah } \\
\text { - } & \text { Menentukan kebijakan } \\
\text { - } & \text { standar provinsi } \\
\text { - } & \text { Menangani masalah lintas } \\
& \text { kabupaten }\end{array}$ \\
\hline 3 & Kabupaten/ Kota & $\begin{array}{ll}\text { - } & \text { Melaksanakan kebajakan } \\
& \text { pemerintah dan provinsi } \\
\text { - } & \text { Menentukankebijakan kabupaten } \\
\text { - } & \text { Menentukan standar kabupaten. } \\
\text { - } & \text { Melaksananakan dan bertanggung } \\
& \text { jawab terhadaap pelaksanaan Wajib } \\
& \text { Belajar } \\
\text { - } & \text { Peremajaan data }\end{array}$ \\
\hline
\end{tabular}

Sumber: diolah dari hasil pembahasan.

\section{Bagan.1. Koordinasi dan Sinkronisasi} Penyelenggaraan Wajib Belajar

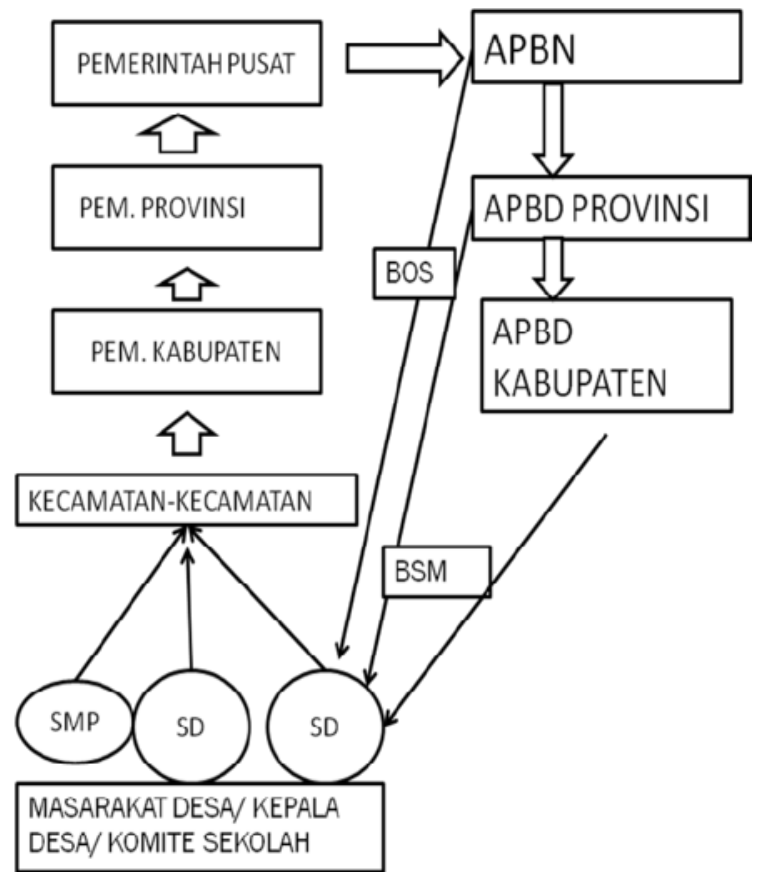

Ujung tombak perencanaan ada di desa (Sekolah Dasar) sesuai dengan kondisi nyata dan standar yang ditetapkan, data/ proposal disampaikan ke kecamatan, dari kecamatan ke Kabupaten, ke provinsi kemudian ke pemerintah pusat.Data dari bawah ini kemudian dibuatkan anggaran belanja dalam APBN, mengalir sebagian pada Provinsi, Kabupaten sesuai posnya masing-masing.

\section{PENUTUP}

\subsection{Smpulan}

Dari hasil dan pembahasan dirumuskan kesimpulan sebagai berikut.

1. Kabupaten Bangli memiliki penduduk sebanyak 213.808 orang dan luas wilayahnya $520,81 \quad$ kilometer. Wilayahnya terdiri dari dataran tinggi pegunungan, tidak memiliki pantai dan satu-satunya kabupaten di Bali yang tidak memiliki pantai. Terdiri dari 4 kecamatan yakni: Kecamatan Bangli, Kecamatan Kintamani, 
Kecamatan Susut dan Kecamatan Tembuku. Kecamatan Kintamani memiliki wilayah yang paling luas dan penduduknya tersebar di lerenglereng bukit dan lembah yang letaknya terpencil di sekitar Danau Batur.Salah satu desa yang lokasinya sangat jauh terpencil adalah Desa Blantih dan Desa Subaya di Kecamatan Kintamani, tetapi masih bisa terjangkau dengan alat transportasi, sehingga, menurut Kabiddikdas Propinsi Bali bahwa di Bali katagori desa terpencil sudah dihapus.APBD Kabupaten Bangli, khususnya PAD sangat terbatas dan belum mampu memberikan bea siswa bagi siswa miskin. Semua guru/ pegawai PNS sudah dianggarkan dan digaji dari Dana Alokasi Umum dan pegawai/ guru honor Kabupaten dibebankan pada APBD Kabupaten.

2. Kendala utama adalah kecilnya APBD dan wilayah yang luas dan berbukit serta penduduk tersebar di antara bukit-bukit. Biaya oprasional sekolah tergantung pada dana BOS dan sumbangan orangtua siswa (yang diputuskan oleh Kepala Sekolah dan Komite sekolah). Dalam upaya mengatasi wilayah yang terpecil dan jarak yang jauh di Kabupaten Bangli dibentuk sekolah satu atap (sekolah dasar dan SMP): ada 8 buah satap di Kabupaten Bangli. Kecamatan Susut ada Satap Pengiyangan, Kecamatan Tembuku ada Satap Desa Kubu Suwih; Kecamatan Kintamani ada 6 yaitu: Satap. 1 Kayu Selem Desa Songan, Satap2. Desa Gunung Bau, Satap3. Banjar Pradi Songan, Satap 4. Desa Pingan, Satap 5 Desa Siakan (sudah ada lembaga belum punya kepala sekolah), Satap 6 Desa Subaya (baru proses pembangunan gedung dan bagi penduduk dapat mengikuti kelas jauh),

3. Untuk mengatasi kesenjangan anggaran pendidikan antara perdesaan dan perkotaan, Pemerintah Pusat, Propinsi dan Kabupaten bekerja bersama-sama dan melakukan koordinasi baik mengenai fasilitas sarana pendidikan maupun sumber daya guru. Trobosan yang dilakukan pemerintah untuk biaya pendidikan dasar adalah melalui pemberian dana hibah. Pemerintah Pusat meluncurkan dana BOS dan Hibah Block Grand, dan Pemerintah Provinsi Bali meluncurkan BSM dan hibah bantuan sarana. Dari penelusuran asal penerima BSM Kabupaten Bangli, maka Kecamatan Kintamani sekolah desa terpecil yang paling banyak menerima BSM Kabupaten Bangli dalam rangka wajib belajar menerima BSM SD sebesar Rp. 2.586.640.000; SMP sebesar Rp 1,913,500,000;Bantuan Prasarana dari Provinsi Bali sebesar Rp. 1.523.000.000. Hibah dari Pemerintah Pusat berupa BOS SD dan SMP Rp. 29.195.200.000, Hibah Block Grand (untuk Kabupaten Bangli ada 2: Sekolah Satu Atap Tembuku dan SMP Gurukula di Kubu, masing-masing memperoleh sebesar Rp.295.154.000,kali $2=$ Rp.590.308.000. Walaupun otonomi ada pada Kabupaten khusus untuk wajib belajar ini pemerintah berusaha memenuhi tanggungjawab negara atas hak memperoleh pendidikan dasar di desa terpencil. 


\subsection{Saran}

1. Masalah hak atas pendidikan adalah bagian dari hak ekonomi, sosial dan budaya dan memerlukan campur tangan negara yang luas baik dalam perencanaan,pelaksanaan, menetapkan standar kebijakan, maupun evaluasi terutama dalam mewujudkan tujuan negara yakni:mencerdaskan kehidupan bangsa.Tanggung Jawab pemenuhan hak ini bukan hanya tanggungjawab negara, tetapi juga masyarakat dan orangtua (melalui komite sekolah). Usaha pemerataan pendidikan dasar sesuai dengan kewajiban konstitusional negara sudah berusaha dipenuhi oleh negara dan sangat tergantung pada sumber daya yang dimiliki. Wujudnya dalam bentuk dana hibah BOS dan Block Grand dari Pemerintah Pusat dan Bea Siswa untuk siswa keluarga miskin (sudah diganti dengan istilah Keluarga harapan) yang langsung masuk rekening sekolah. Untuk di Kabupaten Bangli khususnya di desa terpencil seperti Banjar Subaya, walaupun penduduknya sangat sedikit dan jumlah siswa wajib belajar kurang dari 20 orang, sudah diusahakan dibentuk Sekolah satu atap, SD dan SMP.Suatu hal yang patut dipuji dari pemerintah Kabupaten Bangli dan Provinsi Bali.Demikian juga untuk desa-desa terpencil dilembah kaldera danau Batur lainnya.

2. Koordinasi dan sinkronisasi penyelenggaraan pendidikan harus selalu dilakukan antara pemerintah pusat, provinsi dan kabupaten/ Kota. Pendidikan menentukan kualitas bangsa. Pemerintah Kabupaten dengan jajaran terbawahnya, khususnya satuan pendidikan harus terus melakukan pendataan dan melaporkan kondisi anak didik dan kemampuan penduduk (peremajaan data) dan membuat proposal untuk pembangunan masyarakat.

3. Peranan masyarakat dan pers sangat penting untuk terus mengawasi penggunaan dana hibah agar tepat sasaran walaupun masih relative kecil, jangan sampai diselewengkan. Partisipasi masyarakat dan pers sangat penting terbukti masalah di Desa Subaya segera ditindak lanjuti oleh pemerintah Provinsi Bali.

\section{DAFTAR BACAAN DAN SUMBER INFORMASI.}

Republik Indonesia. Undang Undang Dasar Negara Republik Indonesia 1945.

-, Undang-Undang No. 20 Tahun 2003

Tentang Sistim Pendidikan Nasional

-------, Undang-Undang No.32 Tahun 2004 Tentang Pemerintahan Daerah

-------, Peraturan Pemerintah Republik Indonesia Nomor 38 Tahun 2007 Tentang Pembagian Urusan Pemerintahan Antara Pemerintah, Pemerintahan DaerahPropinsi, dan Pemerintahan Daerah Kabupaten/ Kota (LNRI Tahun 2007 Nomor 82). , Peraturan Pemerintah No.47 Tahun 2008 Tentang Wajib Belajar L N R I Tahun 2008 Nomor 90 dan TLNRI Nomor 4863

-------,Peraturan Pemerintah Republik Indonesia No. 48 Tahun 2008 Tentang Pendanaan Pendidikan LNRI Tahun 2008 Nomor 91

-,Peraturan Pemerintah RepubliK 
Indonesia No.19 Tahun 2005 Tentang Standar Nasional Pendidikan LN.RI Tahun 2005 No.41dan sebagaimana diubah dengan Peraturan Pemerintah Republik Indonesia No.32 Tahun 2013 Tentang Perubahan Atas Peraturan Pemerintah Republik Indonesia No.19 Tahun 2005 Tentang Standar Nasional Pendidikan LNRI Tahun 2013 Nomor 71.

Peraturan Menteri Pendidikan dan Kebudayaan No.51 Tahun 2011 Tentang Petunjuk Tehnis Penggunaan Dana Bantuan Oprasional Sekolah dan Laporan Keuangan Bantuan Oprasional Sekolah.

Peraturan Menteri Pendidikan dan Kebudayaan RI No.161 Tahun 2014 tentang Juknis Penggunaan dan Pertanggungjawaban Dana Bos 2015. diunduh dari www.bos.kemendikbud. go.id, 19-Oktober 2015.

Kepala Dinas Pendidikan Pemuda dan Olahraga Propinsi Bali. 2014. Syaratsyarat pemberian Bea Siswa Bagi Siswa Miskin SD,SPM,SMA dan SMK. Ditetapkan di Denpasar 23 Oktober 2014.diunduh dari www. baliprov.go.id 25 Agustus 2015 Tentang Syarat BSM

Bali Post Senen, 14 Juli 2014.Tempat Sekolah Jauh Tiap Tahun Belasan Siswa SD di Subaya Tak Melanjutkan. Hal.15 kol 2,3,4,5,6.

Ni Ketut Sri Utari, dkk.2014. Laporan Penelitian: Implementasi

Tanggungjawab Negara Terhadap

Kewajiban Konstitusional Warga Negara Mengikuti Pendidikan Dasar,
Program Studi Magister (S2) Ilm Hukum Unud.Denpasar

\section{INFORMAN}

I Nyoman Subrata, Drs.M.M Kepala Bidang Pendidikan Dasar Disdikpora Propinsi Bali beserta staff. di Kantor Disdikpora Propinsi Bali Senen, 21 September 2015, jam. 10.30

I Nengah Danta Haryana,S.Pd,MA. Kabid Dikdas Dikdispora Kabupaten Bangli beserta staff di Kantor Dikdispora Kabupaten Bangli Jalan Brigjen Ngurah Rai No.82 Bangli Selasa 29 